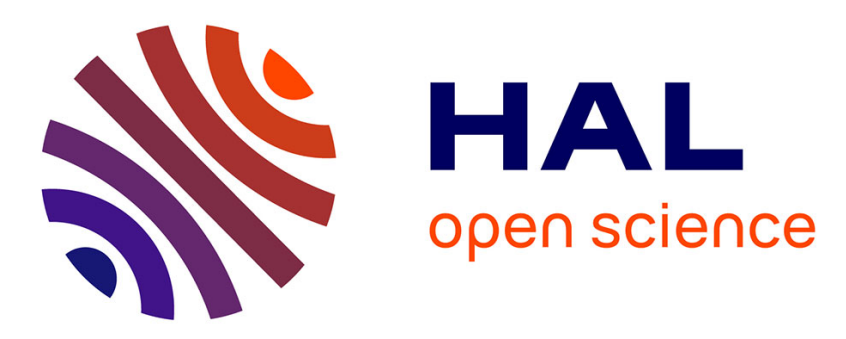

\title{
Infrared welding process on composite: Effect of interdiffusion at the welding interface
}

Andre Chateau Akue Asseko, Eric Lafranche, Benoît Cosson, Fabrice Schmidt, Yannick Le Maoult

\section{- To cite this version:}

Andre Chateau Akue Asseko, Eric Lafranche, Benoît Cosson, Fabrice Schmidt, Yannick Le Maoult. Infrared welding process on composite: Effect of interdiffusion at the welding interface. ESAFORM 2016 - 19th International ESAFORM Conference on Material Forming, Apr 2016, Nantes, France. art.020011 - 6 p., 10.1063/1.4963415 . hal-01609023

\section{HAL Id: hal-01609023 \\ https://hal.science/hal-01609023}

Submitted on 25 Mar 2019

HAL is a multi-disciplinary open access archive for the deposit and dissemination of scientific research documents, whether they are published or not. The documents may come from teaching and research institutions in France or abroad, or from public or private research centers.
L'archive ouverte pluridisciplinaire HAL, est destinée au dépôt et à la diffusion de documents scientifiques de niveau recherche, publiés ou non, émanant des établissements d'enseignement et de recherche français ou étrangers, des laboratoires publics ou privés. 


\title{
Infrared welding process on composite: Effect of interdiffusion at the welding interface
}

\author{
André Chateau Akué Asseko ${ }^{1,2, a}$, Éric Lafranche ${ }^{1, b}$, Benô̂t Cosson ${ }^{1, c}$, Fabrice Schmidt ${ }^{2, d}$, Yannick Le Maoult ${ }^{2, e}$ \\ ${ }^{1}$ Mines Douai, Department of Polymers and Composites Technology \& Mechanical Engineering, 941 rue Charles Bourseul, CS \\ 10838, F-59508 Douai Cedex, France. \\ ${ }^{2}$ Université de Toulouse ; Mines Albi, ICA (Institut Clément Ader) ; Campus Jarlard, F-81013 Albi cedex 09, France
}

${ }^{\text {a) }}$ Corresponding author: andre.akue.asseko@mines-douai.fr, ${ }^{\text {b) }}$ eric.lafranche@mines-douai.fr,
${ }^{c}$ benoit.cosson@mines-douai.fr, ${ }^{\text {d) }}$ fabrice.schmidt@mines-albi.fr, ${ }^{\text {e) }}$ yannick.lemaoult@mines-albi.fr,

\begin{abstract}
In this study, the effects of the welding temperature field developed during the infrared assembly process on the joining properties of glass fibre reinforced polycarbonate/ unreinforced polycarbonate with carbon black were investigated. The temperature field and the contact time govern together the quality of the adhesion at the welding interface. The effect of the semi-transparent glass fibre reinforced polycarbonate composite / unreinforced polycarbonate composite with carbon black interface was quantified in term of quadratic distance of diffusion or diffusion depth through the welding interface. The microstructural characterizations were investigated in order to inspect the welding zones quality and to observe their failure modes. The diffusion theory has then been applied to calculate the variation of the quadratic distance of diffusion versus time at different locations. The complete self-diffusion is supposed occurring only at temperature above the polycarbonate glass transition temperature $\left(140^{\circ} \mathrm{C}\right)$ and with a quadratic distance of diffusion superior to the mean square end-to-end distance.
\end{abstract}

\section{INTRODUCTION}

Our previous studies [1-3] investigated a global analytical model (refraction and absorption phenomena) for modeling of transmission laser/infrared welding process in thermoplastic composites. This model allows describing the attenuation of laser beam, the prediction of heat source in laser welding process thermal simulation in the case of UD thermoplastic composite as well as the evolution of the three dimensional temperature field during the welding process. The part performances in the case of the association of two or more materials depend not only of the own properties of each material but also on their interface and/or interphase properties directed by the assembly process (thermal or chemical assembly). In the case of melted assembly of miscible thermoplastics (thermal welding or comolding processes), the polymer adhesion will be considered depending of the contact time, the surface wettability and chain diffusions $[4,5]$. More than one mechanism contributes to the adhesion of polymers. The mechanical adhesion, the electrical theory, the wettability model, the diffusion or inter-diffusion model, the chemical link theory are generally used to explain the polymer adhesion, each of them being applicable in a specific domain depending of the nature of the welded polymers and the assembly conditions $[5,6]$. In the case of the adhesion of two miscible polymers, the total melting of the whole surface is necessary for the development of the diffusion mechanism $[7,8]$. The adhesion is then characterized by molecular chain entanglement. The molecular aspect at the interface during the diffusion can be described by the reptation model developed by De Genne $[9,10]$ or by the simplified model of the minor chain $[11,12]$.

On the bases of our previous works, this present study focuses on the effects of the welding temperature field developed during the assembly process on the joining properties of glass fiber reinforced polycarbonate/polycarbonate composite. The temperature field and the contact time govern together the quality of the adhesion at the welding interface. The diffusion theory has then been applied according to the Graessley's analytic method [13], to this end. The joining performances will be also evaluated by microscopy analysis. 


\section{EXPERIMENTAL}

\section{Materials}

The materials studied were unidirectional (UD) 40wt\% glass fiber reinforced polycarbonates (PC, Makrolon 2405, Bayer Material Science, Germany). The absorbent polycarbonate was added of $0.0243 \mathrm{wt} \%$ of carbon black.

\section{Infrared welding process}

Infrared welding of composites involves two joining parts: one semi-transparent to the IR wavelengths and the other part is absorbent in the same wavelengths. The two parts are positioned together before the welding. Surface treatments are not need as in the gluing process. The infrared beam energy is transmitted through the semitransparent material and is absorbed within the surface of the second material. The bonding between the two parts allows the heating of the semi-transparent part by thermal conduction. Thus, melting and softening of both materials interface occurs (the bonding between the two parts occurs when $\mathrm{T}>\mathrm{T}_{\mathrm{g}}$ in this area). The energy is deposited at the interface in a localized volume causing the formation of a weld zone.

The experimental device, mentioned below (FIGURE 1), is used for the temperature measurement. A halogen lamp MAZDA GY.6.35 (nominal power: 50W, 12V) is focused by a precision Edmund Optics ellipsoidal reflector with $115 \mathrm{~mm}$ for the diameter and two focal points $(17 \mathrm{~mm}$ and $272 \mathrm{~mm})$. When a light source is placed at the first focal point, the source will refocus at the second focal point. The protected aluminum coating features broadband high reflection through the visible and IR spectra (90\%); it comes to heat the interface of the two materials. The temperature field on the back surface of the absorbent material is measured using again the CS 325 FLIR infrared camera $[7.5-13.5 \mu \mathrm{m}]$.

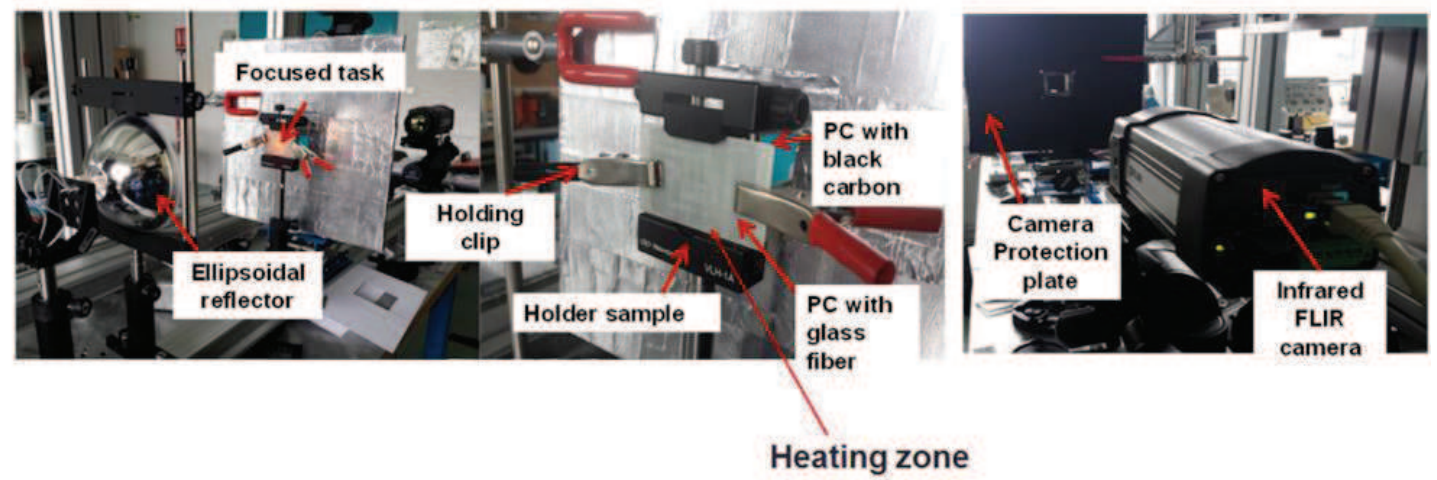

FIGURE 1 : Infrared welding system

\section{Mechanical testing}

The tensile tests of the welded glass fibre reinforced PC/unreinforced black PC samples were performed on a standard tensile machine (Model 1185 Instron, UK) on 3 samples (PC dimensions of 140x21 mm with a welding area of $30 \times 21 \mathrm{~mm}$ ) at a constant cross-head speed of $2 \mathrm{~mm} . \mathrm{min}-1$. The tensile (both polycarbonate samples) or shearing (polycarbonate welding area) strength was then calculated. All the samples were first dried at $50^{\circ} \mathrm{C}$ during 168 hours before testing. The welded sample was tested in tensile mode (shear loading of the weldline).

\section{Rheological characterizations of Makrolon 2405}

The master curves at $190^{\circ} \mathrm{C}$ of polycarbonates (natural Makrolon 2405 and CNT filled Makrolon 2405) were carried out by a strain-controlled oscillatory shear rheometer (Haake Mars III, Thermo Scientific, Germany) equipped with parallel plates of $35 \mathrm{~mm}$ diameter. Linear domains of the material were identified from the strain 
sweep test run from 0.01 to $10^{4} \mathrm{rad} . \mathrm{s}^{-1}$ at a strain of $1 \%$ (this value being the linear domain) and temperature of $190^{\circ} \mathrm{C}, 200^{\circ} \mathrm{C}, 210^{\circ} \mathrm{C}, 220^{\circ} \mathrm{C}$ and $230^{\circ} \mathrm{C}$ to determine $\mathrm{G}^{\prime}, \mathrm{G}$ " and $\eta$.

\section{RESULTS AND DISCUSSION}

\section{Microstructural analysis of the weld zones}

In FIGURE 2 (a) and FIGURE 2 (b), microscopic observations are performed on the welded joint. In the Figure.2 (a), a cross section in the plane system coordinate $(\mathrm{z}, \mathrm{x})$ shows the welded zone in the welding interface. The formation of a weldline between the two materials is noticed. The average width of the weldline is about $45 \mu \mathrm{m}$.

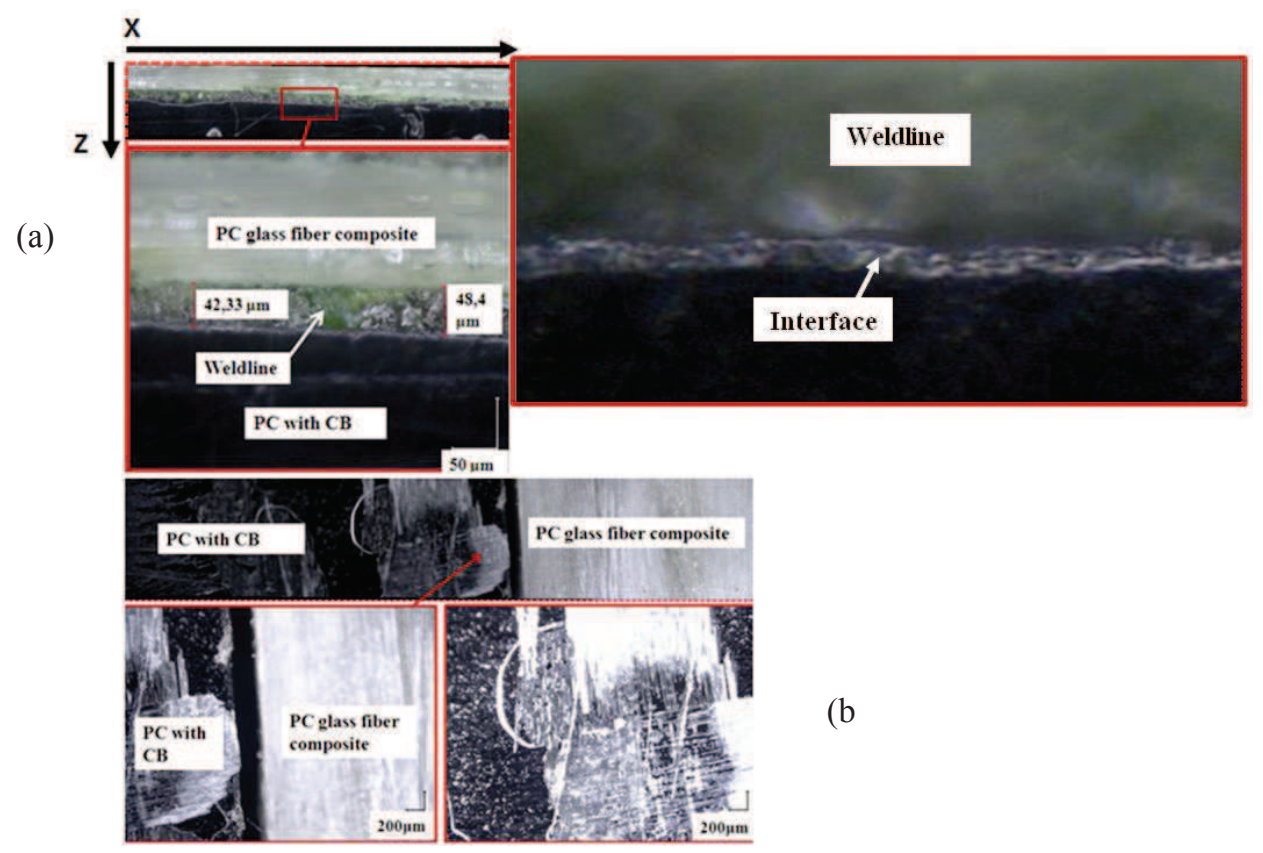

FIGURE 2: Longitudinal section view (a) and the welded joint interface (b)

In FIGURE 2 (b), we carried out a debonding of the welded joint in order to observe its fracture surfaces (the failure was obtained manually). Two failure modes are noted. An adhesive failure which takes place at the welding interface and separating the two welded surfaces cleanly and without carry forward of matter from one surface to the other. However, on a cohesive failure, the two welded parts are mixed up. This failure mode characterizes a good welding quality [14]. In Figure 2 (b), are found the mixed PC glass fiber and PC with CB surfaces in some areas. Macromolecular structures on each side of the welding interface have been mixing in order to establish an entangled network. A cohesive failure of these welded materials is observed. This visual comparison provides the first information on the welding performed quality. The weldline which is observed by optical microscopy shows in fact, a good contact between the two melted composites parts and some irregular surfaces (no visible air cavities in particular). Moreover, the tensile mechanical evaluation of the welding area in shearing solicitation has shown a good performance of the joining zone because the break is occurred on the black polycarbonate part of the sample. The shear strength appeared superior to the tensile strength of the unreinforced black polycarbonate which was broken at 28.8 MPa. (Figure 3). 


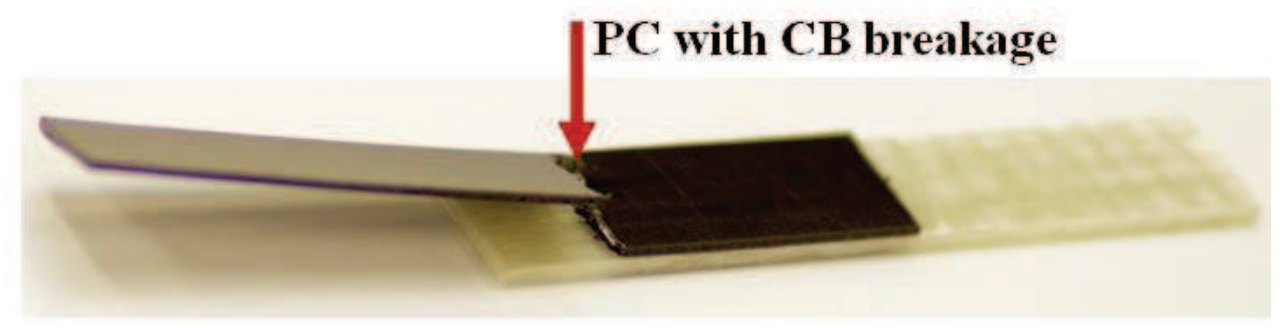

FIGURE 3 : Test result of the welded glass fibre reinforced PC/unreinforced black PC samples

\section{Calculation of molecular self-diffusion at interface}

On the base of the works of De Gennes [9] and Edwards [10, 15], Graessley [13] proposed a self-diffusion coefficient as a function of viscoelastic parameters of polymer:

$$
\mathrm{D}=\frac{\mathrm{G}^{0}{ }_{N}}{135}\left(\frac{\rho R T}{\mathrm{G}^{0}{ }_{N}}\right)^{2}\left(\frac{R_{g}{ }^{2}}{M_{w}}\right) \frac{M_{c}(T)}{\mathrm{M}^{2}{ }_{w} \times \eta 0, M_{c}(T)}
$$

Where $G^{0}{ }_{N}$ is the plateau modulus, $\rho$ is the polymer density, $R$ is the virtual gas constant, $T$ is the absolute temperature, $R_{g}{ }^{2}$ is the mean square end-to-end distance of the chain, $M_{w}$ is the molecular weight, $M_{c}(T)$ is the critical molecular weight at the temperature $\mathrm{T}, \eta 0, \mathrm{M}_{\mathrm{c}}(\mathrm{T})$ is the viscosity at the critical molecular weight at the temperature $\mathrm{T}$. The mean end-to-end distance of chain is fixed at $\mathrm{R}_{\mathrm{g}}=2.015 \times 10^{-8} \mathrm{~m}$ at $463 \mathrm{~K}$ (literature value for polycarbonate [13]. In TABLE 1, all the data and self-diffusion calculation of the Makrolon ${ }^{\circledR} 2405$ polycarbonate at $190^{\circ} \mathrm{C}$ are reported.

\begin{tabular}{|c|c|c|c|}
\hline $\mathrm{G}^{0}{ }_{N}$ & $1.61410^{6}$ & $\mathrm{M}_{e}(\mathrm{~T})\left(\mathrm{g} \cdot \mathrm{mol}^{-1}\right)$ & 2861 \\
\hline$\rho\left(\mathrm{g} \cdot \mathrm{m}^{3}\right)$ & $1.210^{6}$ & $\mathrm{M}_{c}\left(\mathrm{~g} \cdot \mathrm{mol}^{-1}\right)$ & 5723 \\
\hline$R\left(\mathrm{~J} \cdot \mathrm{mol}^{-1} \cdot \mathrm{K}^{-1}\right)$ & 8.314 & $\eta 0, M_{c}(\mathrm{~T})(\mathrm{Pa} \cdot \mathrm{s})$ & 53350 \\
\hline $\mathrm{M}_{w}\left(\mathrm{~g} \cdot \mathrm{mol}^{-1}\right)$ & $38.710^{3}$ & $\eta 0(T)(\mathrm{Pa} \cdot \mathrm{s})$ & 31045 \\
\hline $\mathrm{A}$ & $1.1410^{-16}$ & $\mathrm{E}_{\mathrm{a}}\left(\mathrm{J} \cdot \mathrm{mol}^{-1}\right)$ & $2.01510^{-8}$ \\
\hline$D\left(\mathrm{~m}^{2} \cdot \mathrm{s}^{-1}\right)$ & $4.8910^{-17}$ & $R_{g}(\mathrm{~m})$ & \\
\hline
\end{tabular}

TABLE 1: All data for self-diffusion coefficient calculation

The self-diffusion coefficient depends on the thermo-dependent factors as the polymer temperature, the critical molecular weight, the Newtonian viscosity at the critical molecular mass. Coupling the calculation with temperature variation during the infrared welding stage of the parts, allows accessing to the variation of the self-diffusion coefficient versus the welding time. Considering that the self-diffusion is only possible for a polymer temperature superior to the glass transition temperature $\mathrm{T}_{\mathrm{g}}\left(140^{\circ} \mathrm{C}\right.$ according to Bayer Material Sciences source), the diffusion time can be determined when the temperature in the part reaches the $\mathrm{T}_{\mathrm{g}}$ of the polycarbonate. The quadratic distance of diffusion $\left\langle\mathrm{l}^{2}\right\rangle$ can be expressed in function of the diffusion time by the expression:

$$
\left\langle\mathrm{l}^{2}\right\rangle=2 . D . t
$$

For a distance to the median plan $(\mathrm{z}=0)$, the quadratic distance of diffusion $\left(\left\langle\mathrm{l}^{2}\right\rangle_{\mathrm{z}}\right)$ can be expressed by the area under the Self-diffusion coefficient (D) (Equation 1) versus the diffusion time from the median plan $\left(\mathrm{t}^{\mathrm{z}}{ }_{\text {diff }}\right)$ curves according to Equation 3.

$$
\left\langle\mathrm{l}^{2}\right\rangle_{\mathrm{z}}=2 \cdot \int_{0}^{t_{\text {diff }}^{\mathrm{z}}} D(t) d t
$$


Furthermore, the self-diffusion can only occur at a quadratic distance of diffusion superior to the mean square endto-end distance $\left(\mathrm{R}_{\mathrm{g}}{ }^{2}=4.0610^{-16} \mathrm{~m}^{2}\right)$. Below this limit, the probability of self-diffusion decreases rapidly. The Figure 4 shows the evolution of quadratic distance of diffusion (calculated according to the Equation 2) versus time at the two locations: the measured temperature variation on the center back surface of absorbent part $\left(T_{\text {back surface }}\right)$ and the simulated or calculated temperature at the interface. At the interface (Figure 5), the quadratic distance of diffusion or the macromolecular depth of entanglement $\left(\left\langle\mathrm{l}^{2}\right\rangle_{\mathrm{z}}\right)$ is $1.05510^{-16} \mathrm{~m}^{2}$ according to the equation 3 . Thus, the necessary conditions for a complete self-diffusion have not yet been reached. A perfect cohesion is not established even if the first condition of a welding temperature realized above the glass transition temperature of the polycarbonate is achieved. The welding temperature should be increased to obtain a better cohesion of the welding interface and a perfect chain entanglement. The calculated quadratic distance of diffusion is also inferior to the mean square end-to-end distance of the polycarbonate at the referenced temperature $\left(1.05510^{-16} \mathrm{~m}^{2}<\mathrm{R}_{\mathrm{g}}{ }^{2}=4.0610^{-}\right.$ $\left.{ }^{16} \mathrm{~m}^{2}\right)$.

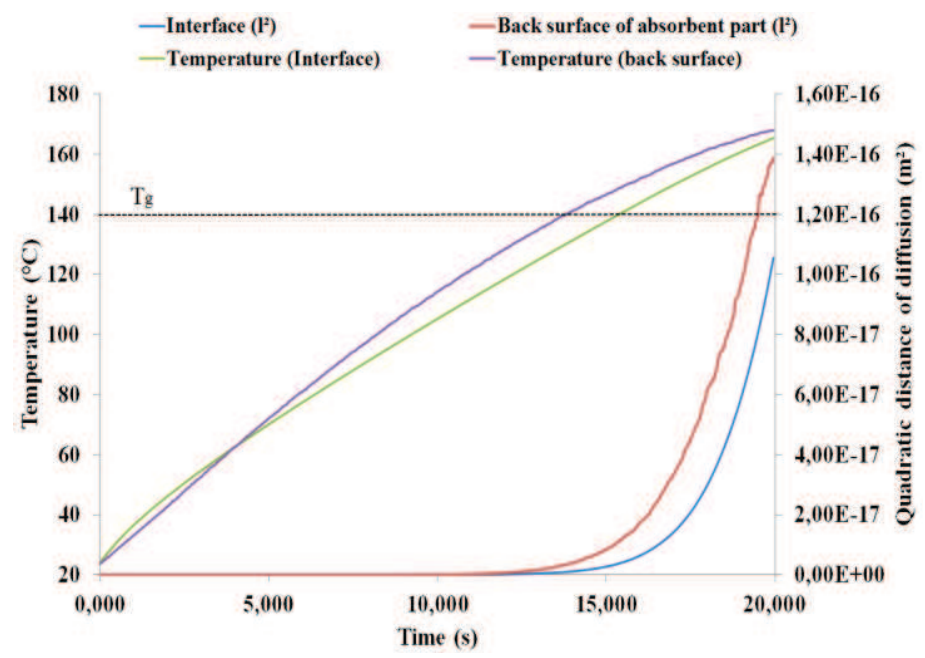

FIGURE 4: Evolution of temperatures versus time: measured on the back surface of absorbent part - simulated at the interface and the respective quadratic distance of diffusion versus time

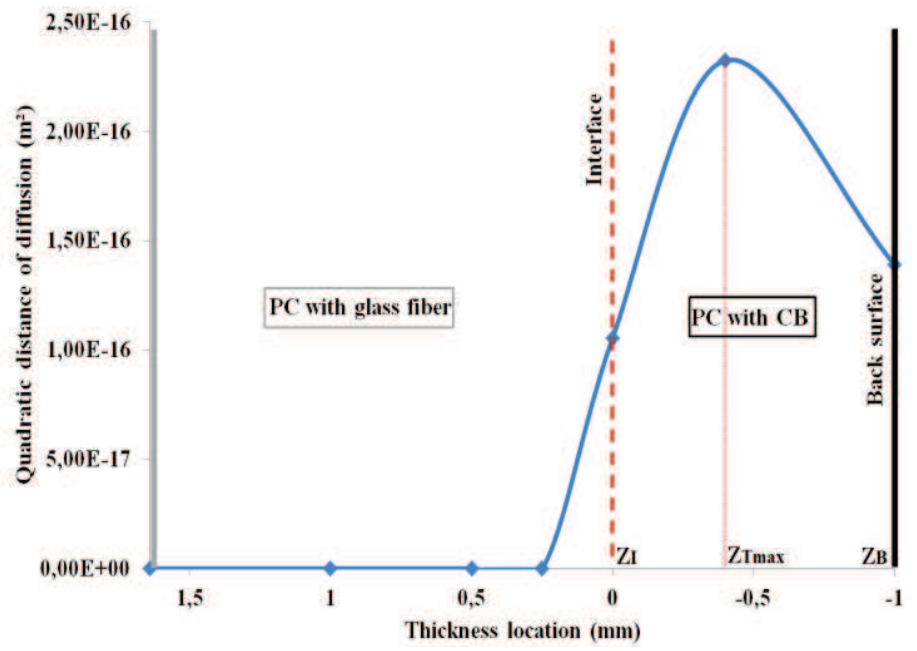

FIGURE 5: Quadratic distance through the thickness

The Figure 5 shows also an increase of the diffusion probability under the interface $\left(Z_{\operatorname{Tmax}}=0.4 \mathrm{~mm}\right)$ due to the volume absorption phenomenon which leads an increase of the temperature revealed at this location. 


\section{CONCLUSION}

This present study was focused on the effects of the welding temperature field developed during the infrared assembly process on the joining properties of glass fiber reinforced polycarbonate composite /polycarbonate with the carbon black. The joining performances were evaluated by microscopy analysis and the results of the observations provided us the first informations on the welding performed quality, by highlighting the failure modes (cohesive and adhesive). It has also been shown: A perfect cohesion (a good interface adhesion) has been revealed by a cohesive failure of welded materials with a formation of a weldline between the two materials. From the interdiffusion which is supposed occurring only at temperature above the polycarbonate glass temperature $\left(140^{\circ} \mathrm{C}\right)$, the necessary conditions for a complete self-diffusion have not yet been reached. A perfect cohesion was not established even if the first condition of a welding temperature realized above the glass transition temperature of the polycarbonate was achieved.

\section{REFERENCES}

1. AC. Akué Asséko, B. Cosson, F.Schmidt, Y. Le Maoult and E. Lafranche, "Analytical and numerical modeling of light scattering in composite transmission laser welding process,". International Journal of Material Forming, 8, 127-135. 2015

2. AC. Akué Asséko, B. Cosson, F.Schmidt, Y. Le Maoult, R. Gilblas and E. Lafranche, "Thermal Modeling in composite transmission laser welding process: light scattering and absorption coupling," Key Engineering Materials Vols. 611-612 (2014) pp 1560-1567

3. AC. Akué Asséko, B. Cosson, F.Schmidt, Y. Le Maoult and E. Lafranche, "Laser transmission welding of composites-Part A: Thermo-physical and optical characterization of materials," Infrared Physic \& Technology, Vol. 72, 293-299, 2015

4. P. J. Cole and C. W. Macosko, Polymer-Polymer Adhesion in Melt-Processed Layered Structures, Journal of Plastic Film and Sheeting, 16, pp 213-222, 2000

5. S. Wu, Polymer Interface and Adhesion, Marcel Dekker Inc, New York, 630, (1982)

6. S.C. Macedo, E. Lafranche, C.I. Martins, C. Douchain, C. Roux, P. Krawczak, Thin wall injectionovermoulding of polyamide6/polypropylene multilayer parts: influence of processing conditions on thermomechanical properties of layer assembly, Int. J. Materials and Product Technology, to be published 2015

7. K. Lamnawar, A. Maazouz, Rheological modelling of the diffusion process and the interphase of symmetrical bilayers based on PVDF and PMMA with varying molecular weights, Rheol. Acta, Vol 51, pp 691-711, (2012)

8. K. UD, H.H. Kausch, J.G. Williams, Fracture mechanics studies of crack healing and welding of polymers,, Journal Material Science, Vol 16, pp 204-210, (1981)

9. P.G. de Gennes, Reptation of a Polymer Chain in the Presence of Fixed Obstacles, Vol 55, N², p 572, (1971)

10. Doi M., Edwards S.F, The theory of polymer dynamics, Oxford Science Publications, 1986.

11. Christine A. Butler and Roy L. Mccullough, "An Analysis of Mechanisms Governing Fusion Bonding of Thermoplastic Composites" ,Journal of Thermoplastic Composite Materials, Vol. 11, No. 4, pp. 338-363 (1998)

12. Y.H. Kim, R.P. Wool, A theory of healing at polymer-polymer interface, Macromolecules, Vol 16, pp $1115-1120$ (1983)

13. W.W. Graessley, Some phenomenological consequences of the Doi-Edwards theory of viscoelasticity, Journal of Polymer Science, Part B, 18, 1, 27 (1980)

14. M.O. Mairagouna, "Approche probabiliste du comportement mécanique des thermoplastiques assemblés par soudage laser," PhD thesis (in French), Ecole des Mines de Paris, 2012.

15. S.F. Edwards, Statistical mechanics with topological constrains: I, Proc. Phys. Soc, 91, 3,513, 1967 